Comparative Philosophy Volume 4, No. 1 (2013): 41-66

Open Access / ISSN 2151-6014

www.comparativephilosophy.org

\title{
MOHIST APPROACH TO THE RULE-FOLLOWING PROBLEM
}

\author{
CHUNG-I LIN
}

\begin{abstract}
The Mohist conceives the dao-following issue as "how we can put dao in words and speeches into practice." The dao-following issue is the Mohist counterpart of Wittgenstein's rule-following problem. This paper aims to shed light on the rule-following issue in terms of the Mohist answer to the dao-following problem. The early Mohist takes fa

(法, standard) and the later Mohist takes lei (類, analogy) as the key to the daofollowing issue. I argue that the way of fa is not viable. Fa comes in various forms, but all of them are regarded as being cut off from everyday life and therefore subject to various interpretations and, hence, incapable of action-guiding. On the other hand, the Mohist lei represents a kind of life world action drama. A lei situates various elements of action in the context of an everyday life scene. I argue that lei is more qualified than fa in answering to the dao-following issue. I also show that lei substantializes what McDowell calls the "course between a Scylla and a Charybdis" hinted in terms of Wittgenstein's idea of "custom," "practice," and "institution" in regard to the rule-following problem.
\end{abstract}

Keywords: rule-following, dao-following, McDowell, Mohist, lei, fa

\section{INTRODUCTION ${ }^{1}$}

“What is it to follow dao (道, the Way)?" is a main theoretical and practical concern that pre-Qin (秦) thinkers unite. In fact, it is also a core issue, with many other issues built around it. By explicating how pre-Qin thinkers frame and answer the daofollowing question, we can carve out the unique face of the prominent thoughts of each pre-Qin school and thinker. This paper concentrates on the Mohist's way to the

LIN, CHUNG-I (林從一): Professor, Graduate Institute of Humanities in Medicine, Taipei Medical University; Professor, Department of Philosophy, National Chengchi University, Taiwan, ROC. Email: cyberlin@nccu.edu.tw

\footnotetext{
${ }^{1}$ The main ideas on the Mohist's approaches to the dao-following question discussed here were presented in my 2012 paper which is in Chinese. In this paper, nonetheless, I aim to develop some of those ideas further and make explicit some of their significances regarding the rule-following debate.
} 
question.

This paper also aims to contribute to comparative philosophy. The western and contemporary counterpart of the dao-following issue is the so-called 'Wittgenstein's rule-following problem.' ${ }^{2}$ On the one hand, the conceptual resources available in the rule-following debate will help my discussion on the dao-following issue. On the other hand, I hope to make insights in my discussion on the dao-following issue which will also make contributions toward the rule-following debate. I will spell out, in the last section of this paper, what the contributions are. But, first, let me sketch out the landscape of my argument to shed light on the main concerns of this paper.

McDowell famously explains the rule-following problem in his own words and cites Wittgenstein to answer the problem: "Wittgenstein's problem is to steer a course between a Scylla and a Charybdis. Scylla is the idea that understanding is always interpretation. We can avoid Scylla by stressing that, say, calling something 'green' can be like 'Help' when one is drowning - simply how one has learned to react to this situation. But then we risk steering on to Charybdis - the picture of a level at which there are no norms... How can a performance be nothing but a 'blind' reaction to a situation, not an attempt to act on interpretation (thus avoiding Scylla); and be a case of going by a rule (avoiding Charybdis)? The answer is: by belonging to a custom (PI 198), practice (PI 202), or institution (RFM VI-31)." (1984, 342) Our survey on Mohist's way to the dao-following question shows that the early Mohist holds a position of Scylla, but the later Mohist finds a course between a Scylla and a Charybdis, which, as you will see in due course, cashes out the ideas of "custom," "practice," and institution."

\section{PROBLEMATIQUE}

As it often turns out in the study of Chinese Classics, our work of the Mohist's way to dao-following issue would consist of not only exegeses but also substantial reconstructions of the material available from the text of the $M o-Z i$. The goal is to pursue Mohist's thought and arguments and to reconstruct them in a way that is both faithful to the text and brings out what is at stake in the Mohist's points with respect to the dao-following problem. This section characterizes how the Mohist conceives the problem.

The dao-following debate comes in two kinds of approaches: the first is a mere conceptual or linguistic one, taken out of the context of practice. For example, the debate on "whether assassinating a tyrant is an assassination of a king," is such a debate if there is no practical issue to be settled in the conversational setting, or with no immediate practical results. The second kind, on the contrary, regards how to determine whether a practice is properly exercised in accordance to the concept or meaning of a term, especially moral terms. The former is a debate only about

\footnotetext{
${ }^{2}$ The key features of the debate include S. Kripke, C. Wright, D. Davison, J. McDowell and R. Brandom.
} 
conceptual or linguistic adequacy, but the latter concerns the evaluation on whether an action is executed, in a real-life setting, according to moral concepts or terms.

The following commentary in "Valuing Righteousness" of $\mathrm{Mo}-\mathrm{Zi}$ nicely indicates that the Mohist understands the dao-following debate as the second conception aforementioned (665-667/47.9). ${ }^{3}$ The commentary is made up of two examples: the blind person example and the gentlemen example.

Now a blind person says: What is white is light; what is black is dark. Even those who are keen-sighted have no way of changing this. [But if you] mix together white and black [objects] and ask a blind person to pick ( $q u$, 取), he is not able to know. Therefore, when I say that a blind person does not know white and black, this does not refer to his naming, but to his pick. Now the way the gentlemen of the world name benevolence. Even Yu and Tang would have no means of changing. [But if you] mix together the benevolent and the non-benevolent and ask the gentlemen of the world to pick, they are not able to know. Therefore, when I say that the gentlemen of the world do not know benevolence, this does not refer to their naming. It too refers to their pick.

Here, two sorts of linguistic knowledge are distinguished: one is involved with the ability to pick ( $q u$, 取, pick, select, take, get); ${ }^{4}$ another is not. "To pick" is the ability to select or make a distinction in accordance with names in an actual situation. A blind person can correctly attribute, in a purely linguistic manner, 'white' to what is light and 'black' to what is dark. However, when encountering a mixture of black and white things, he is unable to tell which are white and which are black. That is, the blind person might possess some kind of linguistic knowledge of color, say, that of composing words, while lacking pick-relevant color knowledge. The blind person example is, however, flaws for the following reason. It is nearly tautological to say that the blind is unable to distinguish visual differences among things. Nonetheless, the gentlemen example that immediately follows would serve the point. Some alleged gentlemen are able to say something correctly about malevolence. However, when facing concrete benevolent and malevolent cases, they might be unable to tell them apart. The gentlemen example is informative, since a so-called gentleman is not, by definition or by nature, one who is incapable of distinguishing the benevolent from the malevolent in real-life situations.

The basic idea of the comment of "Valuing Righteousness" is clear. 'To pick' something means knowing how to properly apply terms to things in a concrete context. With respect to the dao-following issue, this shows that the Mohist regards it as a debate with practical significance instead of a merely linguistic debate. More specifically, a Mohist would understand the dao-following issue as: "In a concrete context, which action should we pick according to a moral term" or "in a concrete

\footnotetext{
${ }^{3}$ All translations are mine unless indicated otherwise; or when they occur as quotations within quotations. Most of my translations are modified versions of Ian Johnston's translation in his 2010, but I take full responsibility for whatever error might result from the modification. All citations to the text of the $\mathrm{Mo}-\mathrm{Zi}$ are to the $\mathrm{Mo}-\mathrm{Zi}$ translated by Ian Johnston (2010) and will be given in the form: page/chapter/line.

${ }^{4}$ I prefer 'pick' for the translation of '取' $(q u)$, because it connotes two senses of ' $q u$ ': one is 'to choose'; the other, 'to get.' The choice of the translation is meant to make the act of select more vivid.
} 
context, how can we make the correct action choice accordance to a moral term?"

We can clarify further the Mohist's view on the dao-following issue, as we take into account the various expositions about "the transmission of dao of ancient sage kings" (667/47.12):

The sage kings of ancient times wished to hand down their dao to later generations. For this reason, they recorded it on bamboo and silk and carved it on metal and stone to transmit and hand it down to their descendants of later generations, wishing these descendants to use it as a model. Now we hear the dao of former kings, but we do not put it into practice. This is to discard the transmission of former kings.

By merely hearing and saying, dao is just transmitted from words to words; by hearing but without practicing, it is not only ignoring dao, but in fact forsaking it; by hearing and then practicing, it is exactly the way to transmit the dao of ancient sage kings. Accordingly, a Mohist conceives the dao-following issue as how we can put into practice dao recorded by words and speeches. In terms of the issue of picking, it is about how we are able to extend from pick-irrelevant to pick-relevant knowledge. This is the problematique that this paper attributes to Mohism. ${ }^{5}$

Mohists will welcome the above interpretation, since Mohism as a whole is interested in practical rather than mere theoretical issues. The following are some examples. "In being in office, although there is learning, it is [right] conduct that is fundamental."(11/2.1) "Use words that are good enough to be put into practice frequently. Do not use [words] that are not realized in practice frequently. Words that are not realized in practice, yet are frequently used, are an abuse of words." $(651 / 46.12)$

It is nearly a consensus that bian (辯, disputation) is the key concept in the Mohist's account of the kind of issue like dao-following. The Mohist sees bian as the prominent method to make and evaluate various kinds of judgment. The Mo-Zi divides the functions of disputation into "making clear the distinction between right and wrong (true and false)," "investigating the pattern of order and disorder," "clarifying instances of sameness and difference," "examining the principles of name and entity," "determining what is beneficial and harmful," and "resolving what is doubtful and uncertain." (621/45.1) The last two sub-functions are directly relevant to the question of picking between right and wrong in a concrete context. The other four can also be so understood. The relevance can also be spotted from the immediately followed commentary where the $\mathrm{Mo}-\mathrm{Zi}$ lays out some related characteristics of disputation, including "enquiry and investigation into how ten thousand things are," "discussion and analysis of the analogies of many words," "names that are the means of picking out entities," "words that are the means of expressing concepts," "explanations that are the means of bringing out causes," "through analogies choices are made; through analogies inferences are drawn," and "what one has in oneself, one does not criticize in others; what one does not have in oneself, one does not demand of others." (621/45.1) These characteristics deserve detailed analysis, but it would

\footnotetext{
${ }^{5}$ In "Explanations A", the explanation or definition of knowledge also includes the notion of realization of intention in action. (445/A81/E)
} 
consume too much space. I will leave this endeavor for another paper. Suffice it to say that they are factors that the agent should take into consideration when making action decisions in a concrete context. For example, "expressing concepts" is the intention to act, “causes" (故, $q u$ ) are reasons that justify and bring out actions, and "analogies" are recognition of patterns of action.

"Disputation" discussed in "Choosing the Lesser" is involved with cause and analogy. "Choosing the Greater" (613/44.20) explains, in terms of the metaphor of "travel via pathway," the roles of cause and analogy in "the set-up of words" and the "move" of words. This also suggests that disputation is closely related to the correct way to follow dao.

As I have said, the main thesis, concerning the issue of Mohist way to daofollowing problem, of this paper is that $q u$ in a "disputation" is the mediation between $d a o$ in words and dao in practice. This shows that the view in this paper on the Mohist's conception of disputation is substantially different from other existent interpretations. Contemporary interpretations of disputation can be divided into three kinds: first, disputation is construed as some kind of inference; second, disputation is construed as some activity able to distinguish or describe correctly; third, the interpretation of disputation is synthesized from the first two kinds, to make inferences based on correct distinction and description. Different as they are, most scholars regard disputation as involving in practice, but their interpretations focuses more on the theoretical aspect out of the concrete context of practice. ${ }^{6}$

In any case, it remains unclear how bian works and whether it suffices an answer to the issue. It remains unclear partly because it is yet to be understood how the two key concepts, lei (類, analogy) ${ }^{7}$ and $f a$ (法, standard, or taking as standard), closely related to bian function in enabling us to put into practice dao recorded by words and speeches, or to extend from pick-irrelevant to pick-relevant knowledge. The main thesis of this paper is that it is $l e i$, rather than $f a$, that will do a superior job in addressing the dao-following issue. With the thesis explained and defended, we shall know better how bian works in answering the dao-following issue.

I will evaluate whether the Mohist disputation suffices bridging pick-irrelevant and pick-relevant knowledge through two approaches: first, through the Mohist concept of $f a$; second, through Mohist concept of lai. 'Analogy' is no doubt the core concept of Mohism. "Words (statements, propositions) proceed according to analogies... If words (statements, propositions) are set up without clarity about analogies, for sure there will be difficulty." (613/44.20) "Through analogies picks are made; through analogies inferences are drawn." (621/45.1)

No less crucial is the concept of 'standard,' because the winning or validity of disputation is determined by standard. "Disputation is contending about 'that' (the

\footnotetext{
${ }^{6}$ Chaehyun Chong (1999) makes a good distinction and explanation about the mainstream views on the Mohist disputation. Again, the mainstream interpretations do not exclude the aspect of practice. However, they do not put emphasis on that aspect. Sun (2005) might be the only exception.

${ }^{7}$ For different purposes, commentators have chosen among 'analogy,' 'kind,' and 'class,' for the translation of lei. I prefer 'analogy,' primarily because it fits more squarely to the main theme of this paper.
} 
other). Winning in disputation depends on validity." (437/A75/C) But "disputation is about making a clear distinction between wrong (true and false)." (621/45.1) For the Mohist, a disputation that no one wins or loses is a disqualified one. The winning or validity of a disputation is determined by whether the disputation is in accordance with $f a$ (standard), as vindicated by the following paragraph: "A standard is what something complies with and is so" $(435 / \mathrm{A} 71 / \mathrm{C})$, or more generally, "Those who work in the world cannot do so without standards and rules. No-one has ever been able to accomplish anything without standards and rules." (25/4.1) In the following, I will evaluate whether disputation (bian) qua standard $(f a)$ suffices a mediator between dao in words and dao in practice.

My discussion of the relation between standard and disputation will not be confined to the works of the later Mohist, such as the six books of "Canons," "Explanations," and "Pick." Nevertheless, my discussion of the relation between analogy and disputation will be confined to those six books. It is so confined, as will be shown below, not only to correspond to the historical development, but also to show the philosophical or theoretical development and advancement of Mohist thought on the dao-following issue.

\section{DISPUTATION QUA STANDARD}

The Mohist insists that the success of a bian (disputation) should depend on its compliance with a certain $f a$ (standard). If bian accords with $f a$, it is valid; if not, then it is invalid. (cf. 623/45.2) If bian is confined only to inference or judgment, then $f a$ plays the role of justification. However, bian, as indicated above, is not only about inference or judgment but also about action guiding. Not merely to talk or to think is always the Mohist's main concern. More specifically, how a proper action is accomplished is the major concern of the Mohist's bian and fa.

Let me sort it out and then examine one by one according to types of $f a$ in the Mo$\mathrm{Zi}$. I will argue that none of them is sufficient to ascertain whether a practice is carried out in accordance with a certain concept or term, so that none of them will render bian sufficient help to mediate between dao in words and dao in practice.

$F a$ comes in different types:

(1) Equipment or instruments for measuring, such as rulers and compasses (see 25/4.1, 259/27.10).

(2) Paradigms of ideal people: the most mentioned ones are virtuous rulers, teachers, and parents. Rulers include Heaven, sage kings, the Son of Heaven, and government leaders (see "On Standards and Rules" and "Exalting Unity").

(3) Written laws or rules of sage kings (see 39/6.1, 201/20.2, 205/21.2).

(4) The principles and maxims that sage kings follow (see 145/15.10).

(5) The models of action and virtues of sage kings (see 157/16.9, 663-665/47.4).

These types of $f a$ have different emphases. As for measuring instruments, $f a$ lays emphasis on methods that evaluate the adequacy of particular cases; as for paradigms 
of people, $f a$ refers to individuals rather than principles; as for written laws or principles of sage kings, $f a$ is expressed in the form of proposition, not of individuals or models of action; as for the principles and maxims that sage kings follow, $f a$ is more abstract and general — sometimes even in the form of ideas (e.g., justice, mutuality, benefit) rather than the written laws or principles of sage kings; as for the models of action and virtues of sage kings, $f a$ refers mainly to some models or characteristics of action, like intentions, which may not be in the form of language. From individuals who have personality to abstract principles or rules and even to ideas, from non-linguistic models of actual actions to written laws or rules, and from lifeless measuring instruments to intentions of sages, the differences among types of standard are enormous. It seems that for the Mohist whatever helps to norm-following practice is $f a$.

\subsection{MEASURING INSTRUMENTS}

Although measuring instrument is an explanatory tool for the standard of government or moral action, it helps us understand some crucial points in the Mohist's general conception of $f a$. Take compass as an example. If we want to draw a circle, a compass helps us draw it; to judge whether a shape is a circle, the compass helps us decide if it is one; when picking a circular shape, the compass helps us decide which one is more circular. Thus, compass is a reliable instrument that makes us transition from the intention of drawing, distinguishing and choosing circles, to the action of drawing, distinguishing and choosing circles; this is a process from the idea of circle to the practice of circle. It is rather clear that the idea of measuring instruments is a useful conceptual device that enables us to explore possible answers to the issue of bridging between dao in words and dao in practice, or putting into practice dao in words.

Taking $f a$ as measuring instruments puts emphasis on its reliability. Reliability is an interesting concept, but I should pass it over till later when discussing "Heaven as

fa." In any case, theoretically, the idea of measuring instrument fails its purpose. A compass is a well-functioning compass because it can reliably draw a typical circle. Without first knowing what a typical circle is, we do not know what a precision compass is. However, if we know what a reliable measuring instrument is, then we know what a correct judgment or action is. This indicates a direct circularity in an answer to dao-in-practice issue in terms of measuring instrument. The circularity will appear in a dao-in-practice explanation if it takes the following form: if the practice of dao follows strictly the standard that governs the practice of $d a o$, it will result in a genuine practice of dao.

\subsection{A PARADIGMATIC PERSON}

For the sake of discussion, let me take the paradigm as a moral paradigm. To be able to learn from a moral paradigm, one has to be able to first recognize one. However, it is noted that one cannot be a morally paradigmatic without her behaviors being reliably moral. Thus, if we know whether a model of moral behavior can be a 
paradigm, we have already known whether a behavior is moral. This shows that taking paradigms as criteria of the correctness of our practice is either redundant or circular. It is redundant, since we can appeal directly to moral behaviors that are essential to a moral paradigm. It is circular, since the very idea of a moral paradigm contains the idea of moral correctness. To put it differently, if we remove the presupposition of a paradigm, models of behaviors of any parent, teacher or governor are no longer able to serve as paradigms. If fact, the Mohist is also aware of this problem: "There are many parents in the world, but few who are benevolent. If everyone took his parents as the standard, this would be a standard without benevolence.... Therefore all three - parents, teachers and rulers - cannot be taken as a standard for bringing about order." (25-27/4.2)

It is in principle not viable to take particular things, such as an individual and a certain behavior, as standards of right behavior. Taking a particular thing as the standard mainly appeals to the similarity between the thing as standard and things to be judged: If they are similar, then they are correct; if not, then not. However, any two things are always similar to some respects and not similar to some other respects. Therefore, unless we can decide the aspect of comparison, we cannot determine the similarity among things and correctness. In other words, it is semantically incomplete and thus indeterminate in truth value to take individuals as subjects of emulation or comparison.

\subsection{WRITTEN LAWS OR RULES OF SAGE KINGS}

Taking the written laws or rules of sage kings as standards, like paradigms, face the circular problem aforementioned, since the concept of sage king contains the concept of paradigm.

Moreover, the laws and rules of sage kings are written in language. Appealing to "standards" in the form of language cannot provide an ultimate answer to the question of how to bridge dao in words to dao in practice. Standards in linguistic form are also kinds of dao in words.

Some written laws and rules are more concrete, like "In ancient times, the sage kings, in establishing their rules for clothes and garments, said: 'In winter, make clothes that are purple or brown in color, and light as well as warm.... and then stop." ' (207/21.4) These types of written laws and rules are so concrete as to describe behaviors that people ought to do. For laws or rules that are so concrete, I think that among those laws and rules there is either, in practice, no need to fill the gap between dao in words and dao in practice, or, in theory, remaining no solution to the question how to bridge that gap. When there is no question about the usage of terms like 'winter,' 'clothes,' 'purple,' 'brown,' 'light,' 'warm,' 'stop,' etc. arises, the question of bridging the gap does not even arise. On the other hand, if we conduct a theoretical investigation without the presupposition that the usages of those primitive terms are unproblematic, the exact issue of our investigation remains; that is, it is still an issue how the rules on clothes made by ancient sage kings, for example, are understood and practiced. 
In fact, the gap between dao in words and dao in practice can easily widen. Let the following quotation explain this point: "...the sage kings of ancient times, in establishing their rules for moderation in use, said: '.... Everywhere they should provide enough for the people's use and then stop.' " (205/21.2) What does "Everywhere they should provide enough for the people's use" mean? For me, it is enough to have a car for transportation. However, for nobles, cars are not just for transportation, but also for luxury. Thus, even if we all agree the saying of ancient sage kings that everywhere they should provide enough for the people's use and then stop there, we still do not know whether some behaviors are adequate.

\subsection{PRINCIPLES AND MAXIMS THAT SAKE KINGS FOLLOW}

Taking as standards the principles and maxims that sage kings follow, like paradigms, face the circular problem aforementioned, since the concept of sage king contains the concept of paradigm, which further contains the concept of standard.

In addition, those principles and maxims are in general abstract and thus require further interpretation, which in turn will induce the problem of infinite regress or the problem of indeterminacy. For example, the Mohist often talks about "universal mutual love" and "exchange of mutual benefit", but what do 'love' and 'benefit' mean? In the whole $\mathrm{Mo}-\mathrm{Zi}$, these two concepts are not explicated. It seems that Mohist considers them so primitive that people understand them well or understand them in the same way. However, it is simply not true. It is not true even when we are dealing with mundane matters, rather than subtle philosophical debate. For example, is beating children for the sake of discipline an act of love? I think it is perennial controversial issue. Or is that an action that benefits children? I think that is still an issue in dispute among the societies, households, and individuals. The things that seem normal to one may be problematic to another person. Therefore, even if we all accept the maxim of sage kings of universal mutual love and exchange of mutual benefit, we may still be unable to judge which behavior is philanthropic or altruistic. We may ask sage kings to clarify this maxim in greater detail. However, theoretically the same problem arises all the while. An infinite regress is made by appealing to written laws and rules in order to answer the rule-following problem that Wittgenstein points out (see 1967, $\S \S 84-87, \S \S 197-198, \S 201$ ).

In short, principles and maxims of sage kings need to be interpreted, but various interpretations are always available. The plurality of interpretations will lead to different practices. The possibility of plurality and indeterminacy of interpretation would thus render the principles and maxims of sage kings incapable of putting dao in words into practice.

\subsection{MODELS OF ACTION AND VIRTUES OF SAGE KINGS}

Again, it should be noted that the kind of explanation of standards runs into the circular problem. 
On the dao-following issue, almost all pre-Qin philosophers take sage kings into account for their answers. They think that taking sage kings as paradigmatic cases for imitation can help us in, if not grasping, at least approaching dao more closely. The debates therein are usually taken to be about what models of actions of sage kings really are, and can thus be settled by tracking the models down. Nonetheless, since the kings are long gone, their recommendations of right action are preserved, at best, only in canons of institutions. The main task of settling the dao-following issue then comes down to be a work of textual interpretation. However, as shown in the previous section, textual interpretation is not a viable way to the dao-following issue as it is understood here: how standards can bridge between dao in words and dao in practice. The point of this section is not to indicate pitfalls of the Mohist's conceptions of 'standard,' but to collect ideas and thoughts therein to construe, in the following section, at best the conception of standard that might suffice its purpose.

\section{STANDARD QUA HEAVEN}

Taking measuring instruments or paradigms of people as standards usually aims to explain that tian (天, Heaven) is the ultimate standard. Sage kings are thought of as moral standards because and only because they follow strictly the Heavenly standard,

and thereby their written laws or rules, their principles and maxims and their models of action or virtues can be real standards. What are characteristics that the Heaven should have in order to make it become the ultimate standard? The five kinds of standards explored in the previous section suggest the following three properties.

(1) Reliability

Reliability plays a pivotal role in the account of measuring instruments. The Mohist says, a craftsman, whether skilled or not, with the help of instruments, can obtain accurate measurement. (cf. 25/4.1) This is so because the instruments in question are assumed to be reliable. Paradigms made of people, such as parents being disqualified as standards partly because they lack the required reliability.

(2) Anthropomorphism

Human behavior consists of kinds of element that are integrated as a whole. An adequate and effective paradigm of a human behavior should possess at least a number of the essential elements that constitute human behavior. Since those elements find home at human behavior, it appears that there is no better paradigm of a human behavior than a human or human-like behavior.

Take action of drawing a circle as example. In making it explicit what a standard is, the Mohist occasionally employs measuring instrument in isolation from other aspects of measurement activity; but, at times, the Mohist conceives it in connection with some other aspects of measurement activity: "A standard: Concepts, compass and circle are three things - together could they be taken as standards." (435/A71/E) This commentary strongly suggests that a standard of circle drawing action should consist of three elements: first, the concept of (the 
intention to) drawing a circle; second, the instrument for drawing a circle; third, the result of the circle drawing. An account of the standard of circle drawing must take care of all of these three aspects of standard: what kind of concept is involved in carrying out the circle drawing activity; what kind of instrument is used; and what kind of result is produced.

If the tri-element analysis of the standard of circle drawing applies to all standards generally, then it is reasonable to expect that the standard set for human activity must be anthropomorphic. After all, every human action has aspects of concept (figuring in the intention of carrying out an action), way of action and resulting action, and it seems that only human, or humanlike beings, have all three of these aspects in their activities.

The kind of agent closest to Heaven, the ultimate standard of all, is a sage king. The $M o-Z i$ describes the way to a sage as follows: "When silent, one should be thinking; when speaking, one should be instructing; when acting, one should devote oneself to affairs...." (665/47.6) Here what corresponds to the aspects of standard exemplified as circle drawing - concept, compass, circle - are thought, speech, action, all of which are aspects of standard exemplified as the sage. ${ }^{8}$

\section{(3) Propositional Content of Standard}

Standards, either as written laws or rules of sage kings, or as principles and maxims they follow, or even as their models of action or virtues, either themselves are propositionally constituted or can be described as so. I believe that the reason why they come with propositional content is for them to be cognizable. In order to be employed in any way, the meaning of a standard must first be cognized by agents.

What kind of characteristic Heaven must have to be the ultimate maxim or the highest principle? First, in the discussion of standard as measurement above, the reliability of standard is manifested. Second, in the discussion of standard as paradigms of people, the multiplex of standards of human behaviors is manifested. Third, in the discussion of standard as written laws or rules, principles and maxims, or models of action or virtue of sage kings, the propositional and cognizable feature of the content of standard is manifested.

The second point above, namely the multiplex of standards of human behaviors, has two possible lines of thought: first, concept, way of action and the resulting action derived from the circle drawing example; second, thought, speech and action derived from the example of the sage. From the first line of thought, we can infer that Heaven, qualified as the highest principle of human behaviors, must be a reliable paradigm. Meanwhile, Heaven must possess concept, way of action and the resulting action so

\footnotetext{
${ }^{8}$ Those qualified by the $M o-Z i$ as sages are the sage kings (see "Heaven's Intention III", section 4) It has to be noted that the Mohist emphasizes these three aspects so specifically that they exclude personal emotions, such as happiness, angry, joy and love; however, this ignores many human aspects of the sage, so that the sage as the paradigm of people becomes less comprehensive.
} 
as to be corresponding paradigms. From the second line of thought, we can infer that Heaven must possess thought, speech and action so as to be corresponding paradigms respectively. These two lines are the same at the levels of thought (concept) and action, but different in that the first is about instrument and the second about speech. They are compatible, since speech can be a kind of instrument.

The relevant commentaries of the Mohist on "Heaven as Standard" and other chapters clearly confirm the line of thought that we trace here. (cf. 27/4.3, 239241/26.6) I should not go into many details here. Suffice it to mention only a famous and representative doctrine "three criteria of a statement" (see 331/36.1 and 339/37.1) concerning "Heaven as Standard." The three criteria of a statement are intentions of Heaven and ghosts, the writings of the former kings and the conduct and governing of government. Even though these criteria are on statements, we can apply them generally to all models of behaviors. It is obvious that the three criteria correspond to concept, way of action, and the resulting action.

If reliability, anthropomorphism, and propositional content are the properties Heaven possesses for it to be eligible to a standard, then one may easily be skeptical about whether it suffices an answer for the dao-following issue or the bridging role between dao in words and dao in practice. This is so mainly because those characteristics are derived from the kinds of standards we have already judged to be invalid, so that the same arguments will render them invalid too. To avoid being overly repetitive, I shall explicate only some of the main points.

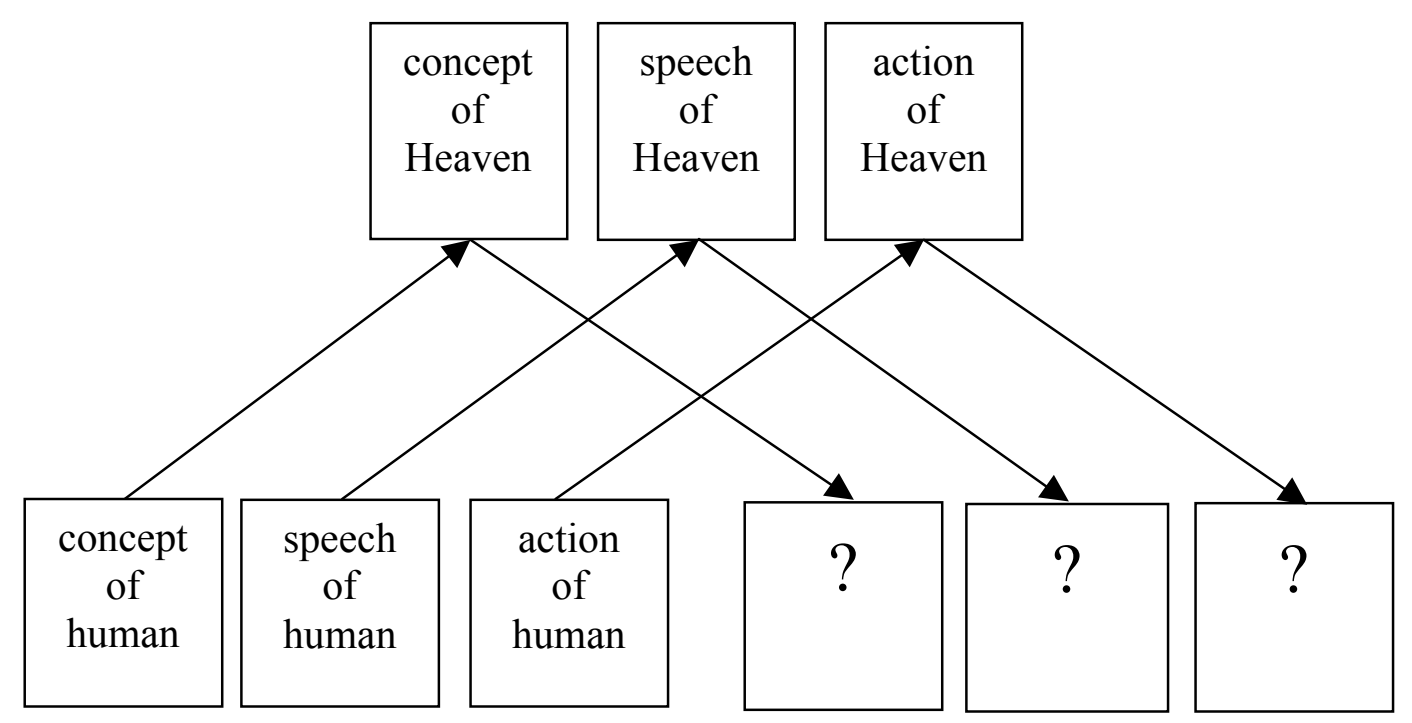

The arrows on the left mean 'emulate,' 'follow,' or 'be similar to (or the same as).' More specifically, the three arrows mean concept of human emulating concept of Heaven, speech of human emulating speech of Heaven, and action of human emulating action of Heaven. These kinds of emulation, as indicated, face several challenges. First, the sages have gone and can no longer present themselves as the 
mediators between Heaven and ordinary people. Heaven thus becomes hardly cognizable. Consequently, people might disagree about concepts, speeches and actions that Heaven actually possesses. For example, people might not agree that 'universal mutual love' and 'exchange of mutual benefit' are some properties Heaven actually possesses. The disagreement accordingly makes emulation indeterminate. Second, even if people reach a consensus on what properties Heaven has, the descriptions of those properties must be interpreted in order to be understood, but interpretation can be made in various ways. In other words, since emulation is related to interpretation and interpretation is multiple, emulation would be indeterminate. Third, even if people reach consensus on the properties of Heaven and their interpretations, Heaven so interpreted is not helpful for our question of how to bridge between dao in words and dao in practice, since the interpreted and so linguistically described properties of Heaven is in fact dao expressed in language but our question is exactly how dao expressed in language can guide our intention, speech and action. ${ }^{9}$

Heaven's intention, and, for that matter, percipient ghosts, almost disappear from the texts of the later Mohist. They have been mentioned only twice in "Choosing the Lesser." In fact, when talking about representatives of standard, the former kings are also gradually fading out off stage. I think it is a theoretical consequence of the Mohist's position. People simply fail to come to a consensus on what the Heaven's intention, speech of the formers kings and their principles and maxims really are. They alone do not show how they should be understood; the context required for a germane interpretation of them is long lost. Controversy over interpretation makes them ineligible of bridging between dao in words and dao in practice. The following commentary from the Han-Fei-Zi indicates the same point here: "Both Confucius and Mo Zi claim to cite Yao and Shun. Their citations are different from each other. Yao and Shun are long gone. Who is to determine which is more authentic?" ("Famous Schools 1")

Moreover, not surprisingly, the later Mohist, especially those paragraphs in the six dialogues of the $\mathrm{Mo}-\mathrm{Zi}$ imply a line of skepticism about the thought of taking sage kings as standard. For example, "Placing: [To say that] Yao was skilled at ruling is to examine the past from the perspective of the present. If one examines the present from the perspective of the past, Yao would not be able to rule." (485/B16/E) "In the case of Yao's righteousness, it is heard of in the present but it is located in the past, and these are different times..." (535/B52/C, see also 535/B52/E) How do we interpret Yao's words, since Yao has passed away for a long time? The emphasis of the early Mohist on the validity and necessity of the former kings as standard is gradually put into doubt.

Once the anthropomorphic standard is removed, the substantial content of standard is also removed and leaves only its form, such as universality, equality, objectivity and reliability. (cf.549/B64/C, 549/B64/E) However, as I have said, the

\footnotetext{
${ }^{9}$ There are two slightly different versions of the three criteria. One appears in "Against Fate II" (331/36.1); the other, in "Against Fate III". (339/37.1) The first renders more support to the viewpoint advocated in the paper, but it is what the later Mohist inherits.
} 
standard of human behavior must consist of the multiplex of the constitutive elements of human behavior. I think this is the reason why, as Heaven and the former kings are no longer considered paradigmatic cases of standard $(f a)$, Xun Zi and Pre-Qin Law School introduce 'the later kings' as a replacement of them.

\section{ANYLOGY AS LIFE DRAMA}

The main purpose of this paper, to review, is to see whether it is "analogy" or "standard" figuring in "disputation" that has the best chance to explain the transition from pick-irrelevant to pick-relevant knowledge, from dao of the former kings to dao-practicing of the later kings, and from dao in words to dao in practice. Previous sections have shown that disputation qua standard fails the task. This section surveys whether disputation qua analogy would do the job.

Let me first sum up some negative points from the previous discussion of standard, and then give some positive points for a qualified Dao-practice mediator. The previous discussion suggests that such a mediator should not possess the following features:

(1) Content that requires interpretation, but allows multiple interpretations.

(1-1) Content that is so abstract as to require interpretation and thus allows multiple interpretations.

(1-2) Content that is so abstracted from everyday life of agents as to require interpretation and thus allows multiple interpretations.

(2) Content that fails to cover all the crucial constitutive elements of human actions so as to be incapable of guiding action.

On the contrary, we may expect a qualified dao-practice mediator to possess the following properties:

(1) Content that can be grasped without (or almost without) interpretation.

(2) Content that includes the main constitutive elements of action, such as concept, way to action, and resulted action.

Both Heaven and ancient sage kings come with all three elements of an adequate dao-practice mediator. However, they are abstracted from the practical context of life, and are thus subject to multiple interpretations. Therefore, it is crucial to see that these three elements have to be closely situated within the ordinary lives of agents seeking for a correct dao-practicing so that agents can grasp the mediator without (or almost without) interpretation and the indeterminacy that follows. Only a definite understanding leads to a determinate action.

That is a crucial turning point. When we situate the concept, way to action and resulted action into ordinary lives of agents, our focus is no longer on individuals isolated from situations, but on situations where individuals reside. We no longer regard those elements as features of any particulars, such as Heaven or sage kings, but 
as constitutive elements of concrete situations. It is a dynamic concrete context, rather than an isolated individual that incorporates concept, way and action. It is like a drama of life. Since it is life, we are in a real sense cottoned on to it. We can easily grasp it without interpretation. For example, let us picture a scenario of the famous Chinese legend Madame White: Madame White (a snake spirit in the form of a beautiful lady) helplessly stands by the shore of West Lake. She is getting wet in the rain. Imagine that you are a young man, single and handsome like $\mathrm{Xu} \mathrm{Xian}$ in the legend, standing nearby with an umbrella. What will you do next? In such a situation, normally and naturally you will do what $\mathrm{Xu}$ Xian does, handing over the umbrella gently. The scenario is an "analogy" in the Mohist sense.

Heaven and the former kings play no role in the analogy as life drama. However, their retirement does not at all mean the retirement of agents. We do not need the later kings, or later sages for the matter, for the replacement, since now we conceive a situation figuring in analogy as everyday life situation. Ordinary people would be just fine, and, in fact, fit more nicely to the scene.

Moreover, the retirement of Heaven and the former kings does not mean the retirement of context of practice, which is required anyway for a successful transaction from pick-irrelevant to pick-relevant knowledge. What the theoretical turn indicates here is that the meditators need no faded-out context wherein Heaven or the former kings set examples, but the context wherein agents are regarded as having successfully realized dao in practice. The paradigmatic context of the kind is the life world of the agents. In fact, since Heaven and sage kings become insignificant after the turn, it is no longer an important issue whether the dao in transmission is indeed the dao that Heaven or sage kings try to transmit. The proper formulation of our issue will be how dao in words and speeches, whether or not it is of Heaven or sage kings, can be put into practice or how to proceed from pick-irrelevant to pick-relevant knowledge.

Accordingly, if "analogy" suffices a dao mediator, it shall have the following interconnected components:

(1) A concrete dynamic situation of life

(2) An agent (or Agents) situated in the above situation

(3) The above agent possesses an intention to carry out a certain action.

(4) A pathway (or means) for the agent to act in the situation.

(5) The agent act via the pathway.

What an analogy manifests is a scenario of action situation, which includes an agent (or agents), an intention typically induced or required by that kind of situation and a model of action. Generally speaking, by providing the scenario of an action situation, an analogy has following functions: Picture that you are in a situation. The situation will manifest the kind of intention, way to action and the resulting action that the situation requires you to have, to follow and to make. Practicing an analogy is like throwing yourself into a particular situation. The situation will "force" you to generate a particular kind of intention; in the meantime, the situation will also provide 
you with the means to realize the intention in action. This function is a unity, whose constitutive elements must be treated as a whole, not as parts.

Corresponding to the understanding of an analogy, the process of its practicing is roughly as follows:

(1) Raise a practical question: How to put the proposition $\mathrm{P}$ into practice.

(2) Identify the proper analogy, PA, for the practice of the P.

(3) Picture that you are placed in the situation that PA describes.

(4) Picture the action you will or should carry out in the PA situation.

(5) Imagine, or better in reality, to act in accordance with the model of action of (4).

This is a process from mere linguistic understanding to practical understanding. In terms of this essay, this process answers how to pick-relevantly grasp a proposition, namely how to proceed from mere verbal understanding of dao to manifesting dao in practice.

Admittedly, the success of analogy-practice is loaded with some substantial presumptions. The most important ones are perhaps the following two:

(1) One has identified the proper analogy for the action-realization of the proposition in question.

(2) One can easily picture oneself being in the situation the analogy describes.

The second assumption usually requires the 'analogy' situations very close to some situations found in the everyday life of the agents who raise the questions. The more one has participated in the type of situation an analogy describes, the more vivid one can picture a situation of the type and so the greater chance of success the analogypractice would come to have. It is true that there is no guarantee of success in an analogy-practice. After all, it involves with various imagined situations, and that may lead to uncertainty and indeterminacy, both in understanding and in practice. However, I am not sure whether the philosophical quest for certainty here is appropriate. After all, what we picture is an everyday life scenario, and facing an ordinary life situation, we grasp it in an instinct and act without thinking.

In other words, in most life situations, we do not think before taking action. Rather, whether or not we have prior intentions or other kinds of thoughts we naturally (or helplessly) enter an intention/way-to-action pattern. In a life situation, the therein naturally arisen intention and the naturally available pathway to action constitute a holistic model, in accordance with which we naturally take a certain action, linguistic or not, which will then be accompanied by newly and naturally arisen intentions and thoughts.

Nevertheless, the first presumption perhaps presents a more serious challenge. One may doubt that our question of dao-following is elucidated at all by "analogy." This is, of course, particularly blatant since the analogy account simply helps itself to the fact that the chosen analogy is a token, in fact, a representative token, of a certain 
dao-following type. If $d a o$-following practices are problematic to a philosopher, then the relevant analogies are merely examples of the problem. I have to confess that I do not know how to resolve the doubt. Perhaps it can be eased by pointing out that the dao-following problem can be treated as a pedagogical one. In a dao-following teaching, the tutor is indeed assumed to have already identified a proper analogy for the action-realization of the content of dao in question. However, there is no such an assumption on the tutee side.

The above is my conjecture on the nature and function of analogy. I will confirm the conjecture directly by appealing to the examples of analogy offered by the Mohist in the chapter of "Choosing the Greater." The chapter is in fact the only place where analogies are given. Contemporary commentators, as far as I know, completely ignore these examples in their accounts of analogy and disputation.

The final two paragraphs of "Choosing the Greater" are of crucial importance for my survey. The first paragraph explicates the structure or process of disputation, (see 613/44.20) and the second cites concrete examples of analogy. (see 615-61/44.21) There are thirteen analogies cited: the abhorrence of harm (惡害, e-hai), stretching (申, shen, extending, expressing, making known), shivering as in taking a chestnut out of fire (鼓栗, $g u$-li, tremble with fear), ${ }^{10}$ directing the lost (追迷, zhui-mi), a stone of dye (譽石, $y u$-shi), ${ }^{11}$ repeating lines of snake skin, a rat in a hole of wall, ${ }^{12}$ a leaking pot, the well above supplied by a river, the hunter's pursuit, the innkeeper, housing honorably the guest (官苛, guan-go), killing a snake. ${ }^{13}$

Unfortunately, these analogies are described in terms of noun or gerund, like a nametape for a painting or picture or show. They are like nametapes of a painting because most of them appear to refer to something very concrete and almost pictorial. Nonetheless, without the suitable timely context and with only nametapes, it is not an easy task at all to track down what they really refer to. In fact, some of them might be a typo or incomplete contents. However, thanks to the hard work of those who perform exegetical endeavors, the contents of some of those analogies are made explicit so that we can consider them further. Let me analyze four of them.

(1) Hunting Pursuit in the Field

According to the exegesis of Zhang Chun-yi (張純一) ( 1936), 'One may learn not to be selfish; the analogy lies in the hunting pursuit' should be understood: "The hunting pursuit is that hunters pursue animals in a field. They do that for the public welfare of farming, not for themselves. From the example that hunters pursue animals so energetically, we can conclude that one can learn not to be selfish and practice it."

\footnotetext{
${ }^{10}$ A different but also reasonable exegesis on 鼓栗 $(g u$ - $l i)$ is 'shivering like vibrating drum.'

${ }^{11}$ A different but also reasonable exegesis on 譽石 $(y u$-shi) is 'poisonous stone.'

${ }^{12}$ A different exegesis has it to depict a pack of hungry rats trapped in a hole underground, ending turning on one another for food.

${ }^{13}$ In the text, it is just si (死, dying). But, most of exegetists understand it as 'killing a snake' which in fact picturing the scene that in killing a snake, the snake's head and tail will help with each other.
} 
This exegesis contains a dynamic situation, including many hunters (most of whom may also be farmers), animals that may damage crops (which might not belong to the hunters), and the hot pursuit of the hunters in order to capture animals. The shared intent of the hunters in this situation is "for the public welfare of farming." Imagine that you are a hunter in that situation, having the same intention of promoting the public welfare of farming, pursuing and capturing animals that damage crops intensively. Imagine you practicing it, you then understand the meaning of "not to be selfish," an understanding that comes with pick-relevant knowledge.

(2) A Rat in a Hole

According to the exegesis of Zhou Cai-zhu (周才珠) and Qi Rui-duan (齊瑞端) (2009), 'a rat in a hole' is explicated as follows: "A A hole' in the old transcript is recorded as 'a wall'. Therefore, a rat in a hole is rather a rat beside a wall. The rat tries to dig a hole in the wall so that it should be removed." Accordingly, "a rat beside a wall" is not just a description of a static situation, but a dynamic situation that contains a rat digging a hole and being damaged the wall, an agent standing near the wall, seeing the rat digging a hole and taking away the rat. In that situation, the intention of the agent is obviously to prevent the wall from damage. Imagine that you are an agent in that situation. Or more concretely, imagine that it is a cold winter. The wall that provides a shelter for you from the cold rain and chilly wind is enduring the damage done by the rat so that you try to remove that rat. Imagine you practicing it, then you understand the meaning of 'to avoid difference in love, to avoid mutual harm,' an understanding in the form of the pick-relevant knowledge.

I will interpret 'although all are loved equally, one man may be selected and killed' in the quotation in accordance with "to avoid difference in love, to avoid mutual harm." The reason is shown in the below discussion of stopping a leak.

\section{(3) Stopping a Leak}

According to the exegesis of Sun Yi-rang (孫貽讓), 'stopping a leak' reveals that “the malfunction of a pot is leaking; stopping a leak makes the storage of water possible." The agent tries to put water into storage with a pot, but finds that the pot is broken and the water is leaking. In order to make the storage of water possible, he tries to repair the leak. Imagine that you are the agent in that situation and practice it all over again. Then you understand the meaning of how one can 'promote benefit and do away with harm,' an understanding in the form of the pick-relevant knowledge. In fact, the leak-stopping analogy says that in order to promote benefit, harm must be done away, which is different from "promote benefit and do away with harm." For conceptually promoting benefit is not necessarily done by doing away with harm. My interpretation echoes with Zhou's interpretation: "The Mozi always discussing 'love and benefit' and 'hate and harm' at the same time, because he thinks that they are mutually interdependent and correlated." Moreover, he says, "If people cannot love mutually and benefit each other, then people will hate mutually and harm each other.'(2008: 163-4) Indeed, his interpretation also implies that if people can avoid hating mutually and harming each other, then they will love mutually and benefit 
each other. This supports my interpretation of "promote benefit and do away with harm' as "to promote benefit, harm must be done away."

(4) The Innkeeper

Fu Shan (傅山) interprets 'The love of man is not about being praised; the analogy lies in the innkeeper' as "The love of man is not for praise and fame, just as an innkeeper treating passengers well is for their well-being." 14 The dynamic situation of this kind contains an innkeeper, passengers who needs rest, and the innkeeper hosting passengers wholeheartedly for their good comfortable rest. Imagine that you are the innkeeper in that situation and practice it. Then you understand the meaning of 'the love of man is not about being praised,' an understanding in the form of the pickrelevant knowledge.

From the viewpoint of "standard" to that of "analogy" is a turn from principles and maxims to concrete situations of ordinary lives, from the hypothetical Heaven and sage kings to normal agents in dynamic situations, and from propositional content to figurative model of action. This turn makes "disputation" able to possess elements of action more properly and more likely to find a solution to the dao-apprehension problem.

\section{THE MOHIST COURSE BETWEEN SCYLLA AND CHARYBDIS}

This section is devoted mainly to manifesting the Mohist course between, and hence avoiding the two seemingly inescapable devastating positions of what McDowell calls Scylla and Charybdis with regard to the rule-following issue. As I have said, my survey on the Mohist's way to the dao-following question will show that the early Mohist holds a position of Scylla, but the later Mohist finds a course between a Scylla and a Charybdis. But, before going on to spell out the Mohist course, let me sum up the main discoveries of my survey on the Mohist's thoughts on the matter.

I believe that all pre-Qin philosophers encounter the issue of what is the correct way to follow dao. The Mohist is no exception. The Mohist conceives the issue as how we can put dao in words and speeches into practice, or how we can extend from the pick-irrelevant to the pick-relevant knowledge. Even though it is generally held that disputation plays the mediating role for the Mohist, it is yet to be determined which of the two concepts, standard and analogy that are closely related to disputation, plays the bridging role more successfully.

The representatives of standard are Heaven and ancient sage kings. Nevertheless, they, together with their intentions, explicit rules, ways to action, and actions, fail the bridging task. They fail in many ways, but primarily because they are to a certain extent abstracted from the practical context of ordinary life, thus they can be interpreted in multiple ways. The plurality of interpretation leads to the indeterminacy of interpretation, which in turn leads to the uncertainty of action choice. The failure of the notion of standard suggests that a successful dao-mediator should embody the

${ }^{14}$ See Zhou Cai-zhu and Qi Rui-duan 2009. 
following features: (1) being grasped without (or almost without) interpretation; (2) possessing the major constitutive elements of action.

My analysis on the examples of analogy the Mo-Zi shows that analogy is a more plausible and promising dao-mediator. An analogy is an action scenario, which includes agent(s) with the intention that commonly and naturally arises to people placed in that kind of situation. The scenario also contains a model of action. With a scenario of an action situation, an analogy functions in the following way: Imagine that you are in the situation depicted by the scenario. That situation will make you have a certain intention and take action in a certain way. This procedure is dynamic, throwing you into a situation, prompting you to have an intention, finding instruments for actualizing your intention within that situation, and taking action. Analogy, insofar as the mediation between the pick-irrelevant and the pick-relevant knowledge is concerned, consists of elements of action, including intention, way to action and action itself, and correlates these elements to the real-life situation of agents. An analogy is a real-life scenario that agents can grasp without serious interpretation. Dao-mediator as analogy renders a certain understanding of dao. It is a certain understanding in practice.

What bearings should the Mohist's approach be to the dao-following issue have on the rule-following issue? What is the Mohist course between, and hence avoiding the devastating positions of Scylla and Charybdis? For the sake of discussion, let me cite once more McDowell's conception of the rule-following problem and the Wittgensteinean answer he proposes to it $(1984,342)$ :

Wittgenstein's problem is to steer a course between a Scylla and a Charybdis. Scylla is the idea that understanding is always interpretation. We can avoid Scylla by stressing that, say, calling something 'green' can be like 'Help' when one is drowning - simply how one has learned to react to this situation. But then we risk steering on to Charybdis - the picture of a level at which there are no norms... How can a performance be nothing but a 'blind' reaction to a situation, not an attempt to act on interpretation (thus avoiding Scylla); and be a case of going by a rule (avoiding Charybdis)? The answer is: by belonging to a custom (PI 198), practice (PI 202), or institution (RFM VI-31).

McDowell's Scylla is close to what Brandom calls 'regulism' with regard to the rulefollowing issue. By 'regulism' Brandom means (1994, 18-19):

a particular model of correctness and incorrectness, roughly Kant's, in which what makes a performance correct or not is its relation to some explicit rule... On this account, acts are liable to normative assessments insofar as they are governed by propositionally explicit prescriptions, prohibitions, and permissions.

Brandom rejects regulism for a broadly Wittgensteinean reason that it generates an infinite regress $(1994,20)$ :

If correctnesses of performance are determined by rules only against the background of correctnesses of application of the rule, how are these latter correctnesses to be 
understood? If the regulist understanding of all norms as rules is right, then applications of a rule should themselves be understood as correct insofar as they accord with some further rule.

If regulism is right, then correctly applying, say, a term requires a rule, which is of propositional content. How one correctly applies the term and correctly applies this rule requires a second rule for its correct application. Then how one correctly applies the second rule requires a third rule for its correct application. The infinite regress will render impossible any application of any term. Hence, no regulist position is an adequate account of normativity.

How does the regress start? An answer is easy to come by if our concern is the general issue: what is it mean to apply a term correctly? If the general issue could be imposed to the application of a term, it can also be raised to a rule which is, after all, of propositional and hence linguistic content. This is one of the arguments that I construed to reject the ideas taking "the written laws or rules of sage kings" or "the principles and maxims that sage kings follow" as a proper answer to the daofollowing question. Laws, rules, principles and maxims, whether or not belonging to ancient sage-kings, are of propositional contents, which in turn invite the infinite regress problem.

However, there is a different answer to the origin problem of the regress; and it not only fits to a Wittgensteinean line of thought squarely, ${ }^{15}$ but also reveals a more general point of my review of the Mohist conception of standard. Why is it that, for any rule, we need a further rule to understand how to correctly apply it? The reason is that nothing, no matter it is a word, a symbol, a picture, a mental image, a chart, a scheme, a proposition, or a rule, as being taken out of its context of use, is selfinterpreting or self-applying. ${ }^{16}$ In other words, anything that is taken out of its context of use requires being interpreted to be applicable and understandable. This is the theoretical motivation of Brandom's regulism: it is the thought that the application of a rule or any linguistic item always requires another rule. Nevertheless, the reinterpretation could be carried out against various contexts, and none of which could be determined as being the only context proper for the reinterpretation. That means, there is more than one reinterpretation available, and there is no way to determine which one is uniquely correct. If a rule can be applied arbitrarily, then it has no determined content; but there is no content that is indeterminate. The point can be put differently as this: if multiple interpretations are available, then every action is

15 "Every sign by itself seems dead. What gives it life? - In use it lives." $(1967, \S 432)$ See also $\$ 85$ and $\$ 87$.

${ }^{16}$ Williams offers an interpretation of the infinite regress argument along this line of thought (1999, 158-9). According to her interpretation, the main target of the regress argument is the view that there are some meaning entity that, when taken in isolation from their uses, could still possess power of representation. McDowell (1984) holds a similar view. He takes it that the infinite regress resulted from the identification of understanding with interpreting faces two unacceptable alternatives: either the regress does not stop, or it appeals to platonistic, self-applying norms taken as the last interpretation, but there is no such a norm which is self-applying. 
in accordance with any given rule on some interpretation and fails for some other, and therefore the very sense of a rule or a norm evanesce. ${ }^{17}$

The "missing of use-context argument" is much more fundamental than the 'infinite regress argument' not only in that the former offers a substantial ground on which latter launches, but also, and more importantly, in that the former has a more general application. The 'missing of use-context argument' applies not only to explicit rule, norm, law, rule, principle, maxim or any other thing with propositional content, but also to anything, propositional or not, modern or ancient, which is taken out of its context of use. The argument has been employed by this paper to disqualify four of the five types of the Mohist's standard, ${ }^{18}$ including a concrete entity like "the paradigms of ideal people" and an abstract entity or property like "the models of action and virtues of sage kings." The use or practice context of each of the four Mohist standards is long lost; hence, they all face the indeterminacy of interpretation. For the same reason, I think McDowell's "Scylla" interpretation of the rule-following problem is deeper than Brandom's 'regulism' interpretation. Unlike the Mohist standard, the Mohist analogy is not "an attempt to act on interpretation (thus avoiding Scylla)", but does it then "risk steering on to Charybdis - the picture of a level at which there are no norms"? To recall, "Scylla is the idea that understanding is always interpretation" (McDowell, 1984, 342); and regulism is the claim that "what makes a performance correct or not is its relation to some explicit rule." (Brandom, 1994, 1819) The reason why regulism expects an explicit rule to determine the correctness of a performance is the belief that the rule will "tell" us what is correct. However, if what the rule "tells" requires interpretation, then the infinite regress is inevitable. Now if there is a way of understanding a rule that is not interpretation, then the infinite regress argument does not follow. That is, an infinite regress will occur if "understanding is always interpretation," no matter the interpretation is carried out by appealing to an explicit rule or on any other kind of thing.

Now let me turn to McDowell's Charybdis. McDowell's Charybdis is a view that to follow a rule or to use a word correctly is a "blind' reaction to a situation," "the picture of a level at which there are no norms". McDowell's Charybdis is close to what Brandom calls "regularism, ${ }^{19}$ to which Brandom cites an introduction from Sellars's $(1967,322)$ :

It consists in substituting the phrase 'learning to conform to the rule...' for 'learning to

\footnotetext{
${ }^{17}$ Wittgenstein puts this point nicely: "Every interpretation hangs in the air together with what it interprets, and cannot give it any support. Interpretations by themselves do not determine meaning." $(1967, \S 198)$

${ }^{18}$ It does not cover the 'equipment or instruments for measurements,' which is easily rejected for the reason of obvious circularity.

${ }^{19}$ The representatives of regularism are Kripke (1982) and Wright (1980). Their regularisms are, however, more complex than what I have described. The regularity in their accounts is couched in communal term rather than individualistic term. But as McDowell points out: "If regularities in the verbal behavior of an isolated individual described in norm-free terms do not add up to meaning, it is quite obscure how it could somehow make all the difference if there are several individuals with matching regularities." $(1984,350)$
} 
obey the rules...' where 'conforming to a rule enjoining the doing of A in circumstances $\mathrm{C}^{\prime}$ is to be equated simply with 'doing A when the circumstance C' - regardless of how one comes to do it... A person who has the habit of doing $\mathrm{A}$ in $\mathrm{C}$ would then be conforming to the above rule even though the idea that he was to do $\mathrm{A}$ in $\mathrm{C}$ never occurred to him and even though he had no language for referring to either $\mathrm{A}$ or $\mathrm{C}$.

Regularism is a position motivated to avoid regulism. Regulism demands practitioners of a rule-following activity to have an interpretational kind of understanding on the rule involved. It is the demand that eventually invites the infinite regress problem. Regularism gets rid of the demand by reducing a rulefollowing activity to regularity in behavior: being correct is just being producing performances that are regular, and there is no serious intellectual requirement on the participators. Performances that manifest regularity may be just "blind" reaction to situations.

Regularism is refuted because it renders the very distinction of correctness and incorrectness impossible. Any set of performances will manifest some regularities, thus any performance will conform to some regularity. Therefore, if 'to follow a rule correct' is identical with 'to conform to some regularity,' then no performance is not an acting in accordance with a rule.

Unlike the Mohist standard, the Mohist analogy is neither McDowell's Scylla nor Brandom's regulism. As I have said, a Mohist analogy refers to an action scenario, which includes agent(s) with the intention that commonly and naturally arises to people placed in that kind of situation and a model of action that people commonly and naturally will take in it. In the first place, both Scylla and regulism demand the practical capacity to act appropriately to be analyzed as a capacity of knowing some object like a rule, a proposition, a norm, a law, a rule, a principle or a maxim which is expected that it by itself will tell the recognizer what to do next. A Mohist analogy is also an object, but it functions merely as a reminder pointing to a corresponding situation. It by itself does not contain substantial semantic content. This can be seen by noting that if there is no situation for an analogy to point to, then the analogy is in vain; and if the situation is right in front of our eyes, the analogy is no longer necessary. That is, an analogy is merely a dispensable tool of reminding of a situation. The key point of employing an analogy is not to offer an object to be cognized, but to invite someone to play or act in a situation. The kind of practical knowledge that an analogy aims to produce is essentially a knowing-how of acting in a situation.

Secondly, both Scylla and regulism presuppose a two-step idea of a rulefollowing activity. Both positions imagine that to correctly follow a rule one has to first grasp a rule and then act upon it. On the contrary, the core of the idea of Mohist analogy is that acting properly in the situation deployed by an analogy is the very same thing as the grasping of the relevant rule or norm. It is an understanding implicit in practice. There is no ontological gap between understanding a rule and acting on it. 
Thirdly, when Scylla and regulism open the ontological gap between a rule and the practice of it, ${ }^{20}$ they are committing to decontextualization of a rule and a false requirement of interpretation of rule, together with the infinite regress and indeterminacy problems that follow. On the contrary, a Mohist analogy either as an action scenario or as a life drama is never detached from everyday life context. There is thus no serious need for an analogy to be interpreted in order to imagine, play and act.

The Mohist analogy is not "an attempt to act on interpretation (thus avoiding Scylla)", but does it then "risk steering on to Charybdis - the picture of a level at which there are no norms"? I do not think so. The Mohist analogy is neither McDowell's Charybdis nor Brandom's regularist.

To recall, a Mohist analogy refers to an action scenario, which includes agent(s) with the intention that commonly and naturally arises to people placed in that kind of situation and a model of action that people commonly and naturally will take in it. Action in a Mohist analogy is not blind, mindless reaction to a situation, since one is acting intentionally in the situation and responding to whatever rational demand arisen from the situation. The movement in an analogical situation is an act of reason. Unlike a mindless reaction, intention and action in the situation of an analogy are subject to normative evaluation. To generate an adequate intention and a proper action is a criterion of successfully grasping an analogy. An adequate intention or action in the situation of an analogy is one that people are commonly and naturally promoted in that situation. As regularism has observed, an adequate performance should be conforming to some regularity which, in our case, is manifested in the performances carried out by the people in a given situation. However, adequacy requires not only the conformity in performance but also the conformity in intention. This is where the Mohist account of rule-following differs from regularism.

Wittgenstein's paradigmatic dialect about the rule-following issue appears in the section 198 of his Philosophical Investigations:

But how can a rule teach me what I have to do at this point? After all, whatever I do can, on some interpretation, be made compatible with the rule." - No, that's not what one should say. Rather, this: every interpretation hangs in the air together with what it interprets, and cannot give it any support. Interpretations by themselves do not determine meaning.

So is whatever I do compatible with the rule?" - Let me as this: what has the expression of a rule - say a signpost - got to do with my actions? What sort of connection obtains here?" - Well, this one, for example: I have trained to react in a particular way to this sign, and now I do so react to it.

But with this you have pointed out only a causal connection; only explained how it has come about that we now go by the signpost; not what this following-the-sign really consists in. Not so; I have further indicated that a person goes by a signpost only in so far as there is an established usage, a custom.

\footnotetext{
${ }^{20}$ The idea is pointed out by Wittgenstein in that "There is a gap between an order and its execution. It has to be closed by the process of understanding." $(1967, \S 431)$
} 
A Mohist analogy, a life drama, of a signpost represents the "established usage" or "custom" of the signpost. To employ an analogy is to train one "to react in a particular way to this sign" by inviting him/her to play the life-drama of the analogy. If the trainee thereby generates the same intention and performance that people who already master the signpost would generate, then the training is completed.

\section{ACKNOWLEDGEMENTS}

I owe many thanks to the three anonymous reviewers who read this essay and offered helpful criticisms and suggestions. The essay is undoubtedly stronger as a result of their inputs.

\section{REFERENCES}

Brandom, Robert (1994), Making It Explicit (Cambridge, MA: Harvard University Press).

Chong, Chaehyun (1999), "The Neo-Mohist conception of Bian (Disputation)", Journal of Chinese Philosophy, 26 (1): 1-19.

Johnston, Ian (2010), The Mozi: A Complete Translation (Hong Kong: The Chinese University Press).

Kripke, Saul (1982), Wittgenstein on Rules and Private Language (Cambridge, MA: Harvard University Press).

Lin, Chung-I (2012), "Fa-Lei-Yu-Mo-Bian: Han-Qu-Zhi-Zhi-Yu-Dao-Zhi-Xing" 法、類與墨辯一含取之知與道之行 [“Fa, Lei and Mohist Bian -- Knowledge in Practice and Dao-Following”] , Dong-Wu-Zhe-Xue-Xue-Bao 《東吳哲學學報》 [Soochow Journal of Philosophical Studies], 25: 1-41.

McDowell, John (1984), "Wittgenstein on Following a Rule", Synthese, 58: 325-363.

Sellars, Wilfrid (1963), "Some Reflections on Language Games", Science, Perception, and Reality (London: Routledge and Kegan Paul).

Sun, Yi-rang 孫詒讓 (1848-1908), Mo-Zi-Xian-Gu 《墨子閒詁》[Explaining the Mo-Zi at Ease]. See the version in Zhang, Chun-yi (1936).

Sun, Chang-Hsiang 孫長祥 (2005), Thought, Language and Action: Mo-Bian in Modern Academic Perspectives (Taipei: Wen-Chin Press).

Williams, Meredith (1999), Wittgenstein, Mind and Meaning: Towards a Social Conception of Mind (London: Routledge Press).

Wittgenstein, Ludwig (1967), Philosophical Investigations, 2nd ed, Ed. By G.E.M. Anscombe and R. Rhees, trans. by G.E.M. Anscombe (Oxford: Blackwell).

Wright, Crispin (1980), Wittgenstein on the Foundations of Mathematics (Cambridge: Harvard University Press). 
Zhang, Chun-yi 張純一 (1936). Mo-Zi-Ji-Jie 《墨子集解》 [Paraphrasing the MoZi] (Shanghai: The World Book Co.).

Zhou, Cai-zhu 周才珠 and Qi, Rui-duan 齊瑞端 (2009), Mo-Zi-Quan-Yi 《墨子全 譯》 [A Complete Explanation of the Mo-Zi] (Guizhou: Guizhou People's Publishing).

Zhou, Fu-mei 周富美 (2008), Essays on Mozi and Han Feizi (Taipei: Kuo-Chia Publishing Co.). 